\title{
Governança e regulação na saúde: desafios para a gestão na Região Metropolitana de São Paulo, Brasil
}

\author{
Governance and regulation in health: challenges \\ for health management in Greater Metropolitan \\ São Paulo, Brazil
}

\author{
Lauro Cesar Ibanhes 1 \\ Luiza Sterman Heimann 1 \\ Virginia Junqueira 1 \\ Roberta Cristina Boaretto 1 \\ Umberto Catarino Pessoto 1 \\ Carlos Tato Cortizo 1 \\ Iracema Ester do Nascimento Castro ${ }^{1}$ \\ Jucilene Leite da Rocha ${ }^{1}$ \\ Jorge Kayano 1 \\ Olinda do Carmo Luiz 1 \\ Renato Barboza 1 \\ Emilio Telesi Jr. ${ }^{1}$
}

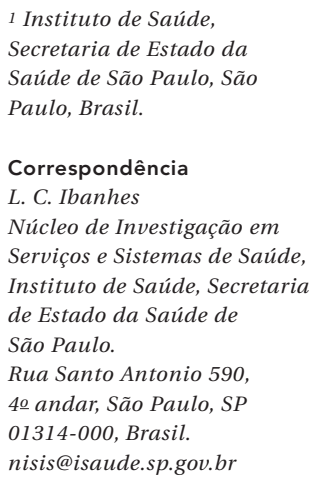

${ }^{1}$ Instituto de Saúde, Secretaria de Estado da Saúde de São Paulo, São Paulo, Brasil.

Correspondência L. C. Ibanhes Núcleo de Investigação em Serviços e Sistemas de Saúde, Instituto de Saúde, Secretaria de Estado da Saúde de São Paulo.

Rua Santo Antonio 590 4 o andar, São Paulo, SP 01314-000, Brasil. nisis@isaude.sp.gov.br

\begin{abstract}
This paper discusses the relationship between the public and private sectors in the Unified National Health System (SUS), based on research whose objective was to identify governance strategies and mechanisms for public/private relations in the health sector, considering the search for equity in Greater Metropolitan Sao Paulo, Brazil. Governance was used as an anatical category, with health system regulation as the issue. Municipal and State health secretaries, members of health councils, and SUS staff were interviewed, and the empirical material was classified as: (a) regulatory mechanisms and instruments; (b) power loci; and (c) actors' positions concerning the SUS and its relationship to the private sector. Mechanisms and instruments have been created and used in the municipalities for regulation of their own services. Regulatory measures for the complementary and supplementary healthcare sector are practically nonexistent. There are numerous institutional power loci, seen more as places for submitting demands than as forums for negotiation. Despite some progress, governance appears to be more of a formal issue. Discussion is needed on the relationship between the public and private sectors and its regulation by municipalities in order to improve the health system.
\end{abstract}

National Health System (BR); Health Systems; Health Management

\section{Introdução}

O artigo discute aspectos centrais da relação público/privado no processo de construção e implantação do Sistema Único de Saúde (SUS) desde a perspectiva do gestor municipal.

A inter-relação público/privado no processo de implantação do SUS assume distintas perspectivas - política, econômica, administrativa, técnica ou jurídica - objetivando tanto impasses estruturais histórico-sociais, tais como a concentração de renda e o predomínio de interesses de grupos específicos e de setores econômicos particulares na conformação do setor, quanto problemas decorrentes das novas estratégias $\mathrm{e}$ redesenho institucionais no marco da relação Estado/sociedade, como o processo de privatização de setores estratégicos (inclusive saúde), o papel das agências reguladoras, a pactuação entre entes federados, dentre outros.

Essa inter-relação expressa a forma e o tipo de inserção e participação dos atores sociais na definição e acompanhamento de políticas públicas. Envolve, necessariamente, a discussão sobre o controle do sistema, redefinindo e reposicionando o Estado em relação ao setor privado na saúde.

No Brasil, a regulação tem como fundamentação a macro política de ajuste econômico, de viés neoliberal, a partir da privatização de setores estratégicos, tais como as telecomunicações e energia elétrica. Por outro lado, para o esta- 
belecimento inicial do que se considera regulação, parte-se da Constituição Federal de 1988 e da legislação do SUS - anteriores ao processo da reforma do Estado da década dos 1990 - frutos dos anseios acumulados por mudanças, inclusão de novos personagens e demandas na história política do país, rumo à plena construção da cidadania e da nação brasileira 1 .

Nos desdobramentos desse entrechoque, cria-se o Plano Diretor da Reforma do Aparelho de Estado 2 que propunha aumento da capacidade do Estado em implementar eficientemente as políticas públicas, no que denomina de "recuperação da governança”, classificada como problema de âmbito "econômico-administrativo" e definida como "capacidade financeira $e$ administrativa de implementar decisões políticas tomadas pelo governo" 3 (p. 49-50). Em Um novo Estado para a América Latina 4 , o então ministro brasileiro encarregado da reforma e redesenho das funções do Estado reafirma que governabilidade e governança são dois "objetivos intermediários fundamentais” da reconstrução do Estado na América Latina 3,4. E estabelece a seguinte distinção entre governabilidade e governança: alcançar a primeira implica construir um Estado democrático que seja politicamente forte. Já a segunda pressupõe a construção de mecanismos capazes de implementar as decisões tomadas, levando-se em conta aspectos financeiros, estratégicos e administrativos.

Quanto ao setor saúde, o âmbito da relação público/privado é estabelecido pela Constituição Federal de 1988, no qual é criado o SUS, regulamentado de acordo com princípios e normas estabelecidas pelas Leis no. 8.080/90 5 e $n^{\circ} .8 .142 / 90$, que prevê integração de atividades e serviços de saúde descentralizado por regiões, e também participação da comunidade por meio de fóruns deliberativos - conselhos municipais, estaduais e nacional.

De acordo com a Lei Federal no. 8.080/90 5, o setor privado participa de modo complementar ao sistema, por meio de convênios e contratos com o setor público (setor complementar). A relação com esse setor tem sido regulada sucessivamente pelas Normas Operacionais Básicas 01/93 7, 01/96 8 e a Norma Operacional de Assistência à Saúde (NOAS/2002) 9, que operacionalizam a descentralização e municipalização do sistema, a integração das ações preventivas e curativas, a regionalização do sistema.

Os seguros e planos privados (setor suplementar) de saúde são regulados pela Lei Federal no. 9.656/98 10 que dispõe sobre: criação de um plano-referência onde consta, (i) cobertura para agravos anteriormente não incluídos; (ii) impedimento da rescisão unilateral dos contratos; (iii) preservação de direitos de aposentados, desempregados e recém-nascidos na vigência do contrato; (iv) atendimento às urgências e emergências; e (v) limitação de prazos de carência. Prevê ainda ressarcimento ao SUS dos procedimentos realizados por beneficiários das seguradoras nos serviços estatais, nos privados contratados e filantrópicos conveniados.

No caso brasileiro, o reaparelhamento do Estado nessa nova conjuntura trouxe consigo a concepção de agências regulatórias, sendo que na área da saúde foram criadas duas agências: a Agência Nacional de Vigilância Sanitária (ANVISA), voltada para o setor da vigilância sanitária, e a Agência Nacional de Saúde Suplementar (ANS), dirigida para o Setor Suplementar da Assistência, basicamente para o mercado, na dupla tentativa de, por um lado, regular e estruturar mercados, onde havia basicamente atuação pública, e, por outro lado, garantir que o mercado se oriente por regras claras e definidas, num ambiente de competição. Vale ressaltar que, nesse caso, o objeto da ação regulatória é um produto sujeito à compra e à venda, no caso a assistência médica a cargo de prestadores apresentada sob a forma de planos de saúde.

Nesse sentido, já se observou que no Brasil as agências têm sido criadas assumindo diversos tipos de competências, e com distintos estatutos jurídicos, desde a administração direta até formas autárquicas, o que aponta para a premência de definir mais claramente atribuições, competências e sua posição no interior da estrutura do Estado ${ }^{11}$.

Regulação aparece como uma maneira de propiciar eficiência econômica e estaria a serviço dela. Além disso, a regulação promoveria o bem-estar de consumidores e usuários, ao mesmo tempo em que incentivaria investimentos necessários para o desenvolvimento econômico. O papel do Estado passa a ser o de estabelecer regras definidas para atuação dos mercados, o que configuraria a passagem de um Estado prestador para um Estado regulador 11.

Observa-se que às agências atribuem-se diversas competências, como as de Executivo, com as atribuições de concessão e fiscalização; de Legislativo, com atribuições de criação de regras e procedimentos com força normativa; de Judiciário, com função de julgamentos, imposição de penalidades, interpretação de contratos e obrigações. 


\section{As dimensões da governança como categoria de análise}

Entende-se governança como "ferramenta analítica para compreensão dos fatores que organizam a interação dos atores, a dinâmica dos processos $e$ as regras do jogo" 12, e estuda-se sua emergência no âmbito da regulação, no marco da relação público/privado no interior do sistema de saúde.

Mesmo com a profusão de estudos sobre o tema, o aspecto central da questão, a conformação estrutural e a configuração política dos liames Estado/sociedade permanecem. E a "confusão terminológica" sobre as possibilidades de incorporação de novas demandas, interações, processos e regras assumem distintos papéis no debate atual: ora a noção de governança se apresenta como "avanço" e "incorporação de novos atores e demandas sociais", ora é entendida como cabeça de ponte dos "interesses transnacionais" e das "agências financeiras internacionais".

Propõe-se utilizar o conceito de governança para compreender os fatores que organizam a interação de atores, a dinâmica dos processos e as regras do jogo, envolvidas na tomada e implementação das decisões em uma dada sociedade. Portanto, como categoria analítica, diferentemente de seu uso prescritivo ou normativo 12 .

A construção das regras do jogo constitui uma dimensão central, uma vez que os concertos entre os atores indicam determinado tipo e grau de institucionalização, comportamentos e condutas. As regras são conseqüência da interação dos atores, que se repõe na conformação da dita interação, e do próprio jogo: são as distintas posições, inserções, recursos ou interesses carreados e/ou demandados no jogo que determinam e explicam o tipo de relação ou interação predominante em dado momento na configuração do sistema de saúde.

Considera-se em sua operacionalização que: "las normas que definen las reglas del juego se convierten en instituciones, se basan sobre valores y creencias e que hay competición estratégica entre individuos y grupos, utilizando técnicas y maniobras para imponer normas" 12, lembrando que estas são de três tipos: meta-normas, isto é, os princípios envolvidos; as normas constitutivas, que refletem a organização do grupo; e as normas regulativas, referentes às decisões tomadas.

Se as regras de jogo são geradas como conseqüência da interação dos atores, os processos se referem à perspectiva temporal, no desenvolvimento seqüencial e dinâmico das transações realizadas. Nesta pesquisa as referências às ações, iniciativas, prioridades apreendidas na fala dos gestores constituíram-se em material empírico para a análise dos processos.
O que se pretende enquanto objetivo é identificar aspectos da governança através dos fatores que influem sobre as dinâmicas, processos e regras do jogo, de modo a compreender como estes mesmos fatores condicionam não apenas o desempenho do sistema de saúde, mas levam à sua própria conformação.

\section{Metodologia}

A pesquisa foi desenvolvida por meio de estudo de casos, tendo sido selecionados cinco municípios da Região Metropolitana de São Paulo, Brasil. Constituída por 39 municípios, a região concentra $10 \%$ do total da população brasileira, $18 \%$ do Produto Interno Bruto (PIB) nacional, sendo que $44,2 \%$ de sua população são beneficiários de planos de saúde.

Inicialmente, para o reconhecimento das desigualdades entre os municípios da Região Metropolitana de São Paulo, os mesmos foram agrupados e hierarquizados com base nos seguintes índices: Índice de Desenvolvimento Humano (IDH) 13; Índice de Condições de Vida e Saúde (ICVS) 14; Índice de Respostas de Serviços de Saúde (IRSS) 14 e Índice Paulista de Responsabilidade Social (IPRS) 15.

A partir de critérios a seguir explicitados, foram identificados os cinco municípios-caso, a saber: São Paulo, Osasco, Guarulhos, Santo André e Franco da Rocha.

Uma particularidade dos municípios escolhidos é o de serem sede das Direções Regionais de Saúde (DIR), conforme definido pela Secretaria de Estado da Saúde. Quatro deles têm mais de 100 mil habitantes, e tendem a apresentar melhores indicadores do que os municípios pequenos da mesma região. Entre os municípios selecionados, três apresentam valores de ICVS acima da média dos 39 municípios da Região Metropolitana de São Paulo (média $=0,652$ ) e dentro do intervalo entre a média e um desviopadrão ( $\mathrm{DP}=0,067$ ), e dois municípios acima da média mais o desvio-padrão. Quanto ao IRSS, quatro municípios estão dentro do intervalo entre a média mais ou menos um desvio-padrão $(0,679 \pm 0,065)$, e um município acima da média mais um desvio-padrão.

Posteriormente, para identificar as desigualdades na assistência à saúde entre o setor público e privado, foram analisadas as seguintes bases de dados: Pesquisa de Assistência Médico Sanitária (PAMS; conduzida pelo Instituto Brasileiro de Geografia e Estatística, IBGE, em 2002 16); Pesquisa de Condições de Vida (PCV) 17; Informações em Saúde (DATASUS) 18; Informações sobre Operadoras de Planos de Saúde (ANS) 19. 
A base de dados para o estudo da oferta e produção dos serviços de saúde na rede pública SUS e da rede particular na Região Metropolitana de São Paulo e nos municípios-caso foi a PAMS/2002 16. Essa é uma pesquisa censitária, realizada por meio de entrevistas, abrangendo todos os estabelecimentos de saúde existentes no país que prestam assistência à saúde individual ou coletiva, de acordo com normas estabelecidas pelo Ministério da Saúde, em regime ambulatorial ou de internação, inclusive os de diagnose, terapia e controle regular de zoonoses, públicos ou particulares, com ou sem fins lucrativos.

O universo da pesquisa PAMS/2002 16 foi composto pelos estabelecimentos de saúde que, possuindo espaço delimitado para uma ação de saúde realizada por um profissional de saúde, pudessem ser enquadrados em um dos critérios estabelecidos para a definição do universo.

Para dimensionamento do problema de saúde que foi eleito o traçador da pesquisa, foram realizados estudos exploratórios nos seguintes bancos de dados, obtidos através da página eletrônica do DATASUS (http://www.datasus.gov. br) no período de 1998 a 2002: Sistema de Informação Ambulatorial (SIA), Sistema de Informação Hospitalar (SIH), Sistema de Informação de Mortalidade (SIM), Sistema de Informações sobre Orçamentos Públicos em Saúde (SIOPS) e Informações em Saúde. Tais estudos apontaram as doenças do aparelho circulatório como traçador adequado tanto na Região Metropolitana de São Paulo quanto nos municípios-caso, para avaliar a utilização dos serviços de saúde pela população SUS e por beneficiários de planos de saúde.

As doenças do aparelho circulatório, em particular as doenças isquêmicas do coração, reúnem várias peculiaridades que permitem sua adoção como traçador - ou condição marcadora - da pesquisa. A magnitude da morbi-mortalidade por essas doenças, a existência de técnicas assistenciais estabelecidas, bem aceitas e de efetividade comprovada, a necessidade de diferentes níveis de atenção para seu controle, inclusive de alta complexidade, sua especificidade na realidade metropolitana de São Paulo e o concurso dos equipamentos e serviços privados, bem como a necessidade de articular diferentes ações, são características que atendem aos requisitos propostos para a definição do traçador.

$\mathrm{Na}$ formulação do projeto definiu-se que a seleção do traçador ocorreria no decorrer da pesquisa, após análise dos índices ICVS e IRSS para a Região Metropolitana de São Paulo, bem como da análise de freqüência de queixas dos consumidores de planos e seguros de saúde aos órgãos de defesa do consumidor.
Do ponto de vista teórico-metodológico, empreendeu-se também exaustivo levantamento bibliográfico sobre os conceitos centrais da pesquisa - regulação, governança, eqüidade, público e privado.

Inúmeros seminários envolvendo o objeto da pesquisa foram realizados, e dentre estes destaca-se a realização do seminário A Relação Público e Privado: Concepções e Experiência Brasileira, em setembro de 2003, com a apresentação seguida de debate, de material teórico especificamente elaborado pelos Professores Doutores Roberto Romano (Universidade Estadual de Campinas), Laura Tavares Soares (Universidade do Estado do Rio de Janeiro) e Emir Sader (Universidade de São Paulo e Universidade do Estado do Rio de Janeiro), com a participação de mais de uma centena de gestores, técnicos e estudiosos do tema, constituindo-se como material subsidiário da pesquisa.

Foram realizadas entrevistas semi-estruturadas com informantes-chave dos cinco municípios-caso, no período compreendido entre os meses de fevereiro e abril de 2005, a saber: sete entrevistas com secretários municipais, sendo cinco dos municípios-caso e duas como pré-teste do instrumento; dez entrevistas com conselheiros municipais; entrevistas com profissionais das áreas técnicas de Planejamento e Programação, Avaliação e Controle e de outras áreas técnicas dos sistemas municipais de saúde. Também foi entrevistado o Secretário Adjunto da Secretaria de Estado da Saúde de São Paulo, além de técnicos do nível central desta secretaria, e a gerente de integração com o SUS da ANS, perfazendo 21 entrevistas, de modo a fornecer amplo mosaico capaz de cobrir os aspectos focados pelo estudo, na Região Metropolitana de São Paulo como um todo.

As questões principais foram elaboradas com intuito de complementar informações acerca das relações estabelecidas entre o setor público, na figura da secretaria municipal de saúde, e o setor privado de prestação de atenção médica, mais precisamente o setor suplementar do SUS formado pelos planos e seguros de saúde.

Após a devida categorização, as entrevistas foram submetidas à análise de conteúdo 20 , sendo seu produto apresentado na forma de mecanismos e instrumentos de regulação; espaços de poder interinstitucional de regulação; e posição dos atores sobre a relação público/privado.

Foi possível identificar como cada um dos atores descreve e analisa sua ação, assim como a dos demais agentes no processo do cotidiano de trabalho, revelando distintas concepções do sistema de saúde. 


\section{Resultados e discussão: mecanismos, espaços e posição do ator SUS na regulação da relação público/privado}

Apresentaremos de modo agregado os temas a partir de sua emersão nas falas dos três segmentos identificados, categorizados em: Mecanismos e Instrumentos de Regulação; Espaços de Poder Interinstitucional de Regulação; e Posição dos Atores sobre a Relação Público/Privado. Os números entre parênteses se referem ao número de atores que citaram o evento.

\section{Mecanismos e instrumentos de regulação}

\section{- Secretários municipais de saúde}

Serviço de Atendimento de Urgência - SAMU (4); plantão regulador (local e regional) de vagas para internação (1); pesquisa telefônica de satisfação do usuário (1); auditoria médica técnica (1); avaliação SIA/SUS (1); avaliação da produção (1); Unidade de Avaliação e Controle - UAC (1); central de vagas (3); plantão regulador de urgência/emergência (2); central de agendamento de consultas do nível regional - DIR (1); central de agendamento municipal para exames e consultas de especialidades (2); relatório mensal de produção (2); software de controle de medicamentos e materiais (2); planilhas de controle da produção e qualidade dos exames (1); painel de monitoramento (1); balanço dos programas (1); comitê de morte materna (1); comitê de mortalidade infantil (1); sistema de cadastramento de pacientes nas unidades básicas de saúde - UBS (1); receita em duas vias (1); teto financeiro (1); contrato de metas com os contratados (1); supervisão regional dos serviços próprios (1); reunião mensal com diretores de serviços (1).

\section{- Conselheiros representantes dos prestadores}

Fiscalização dos serviços (1); pesquisa de satisfação do usuário (1); informatização da farmácia (1); cartão do usuário (1); Programação e Pactuação Integradas - PPI (2); Conselho Municipal de Saúde - CMS (1); comissões do CMS (2); Plano Municipal de Saúde (1); informatização em geral (1).

\section{- Conselheiros representantes dos usuários}

Informatização da farmácia (1); fiscalização dos serviços por meio de visitas (1); pesquisa de satisfação do usuário (1); cartão SUS (1); UAC (1); CMS (1); comissão de finanças do CMS (1); conselho gestor de unidades (1); subprefeituras (1).
O SUS é entendido em sua parcialidade como um conglomerado de serviços que prestam assistência médica e paramédica, nos diversos níveis de complexidade de atenção. Esse complexo assistencial é visto, de modo geral, formado tanto pelos serviços próprios estatais como pelos privados contratados e/ou conveniados.

Em contrapartida à baixa ou nula capacidade de regulação do setor saúde como um todo, seja por razões de escassez de instrumentos e informações, por desuso do raciocínio epidemiológico ou pelo "baixo consumo das informações epidemiológicas" - nos dizeres de um secretário - as tentativas de organizar principalmente o funcionamento dos próprios estatais são mais freqüentes. No entanto, seja pela figura do cartão do paciente, cartão SUS ou das "duas vias da receita", estes mecanismos atingem muito mais o paciente/usuário criando obstáculos ao atendimento do que propriamente a regulação do sistema.

No que se refere aos conselheiros representantes, tanto dos prestadores, como dos usuários, além dos secretários, uma recorrência é a informatização dos sistemas, seja de compras, estoques ou consultas. Por outro lado, vale registrar o posicionamento do secretário que reclama da falta de consumo das informações epidemiológicas, uma vez que o SUS possui um dos maiores bancos de dados informatizados, o DATASUS.

Também na fala desses atores as práticas e instrumentos de regulação sugeridos se situam no campo dos serviços prestados; repete-se a percepção do SUS como um sistema de prestação de assistência médica, passando ao largo a transcendência da autoridade sanitária como responsável pela saúde da população, e saúde sendo entendida não somente como ausência de doença, mas como direito de acesso a bens de usufruto coletivo que reduzam o risco de doenças e outros agravos.

\section{Espaços de poder interinstitucional de regulação}

\section{- Secretários municipais de saúde}

DIR (3); Comissão Intergestores Regional - CIR (1); CMS (3); conselho gestor de unidade (2); Secretaria Municipal da Fazenda (1); Associação Paulista de Medicina (1); Secretaria Estadual de Saúde (1); corporação médica (1); Fórum Metropolitano (1); Câmara Municipal (1); Conselho dos Secretários Municipais de Saúde - COSEMS (1); comissão intergestores bipartite (1); movimentos sociais organizados (1). 


\section{- Conselheiros representantes dos prestadores}

DIR (2); CMS (2); orçamento participativo (1); comissões ou câmaras técnicas dos CMS (1).

\section{- Conselheiros representantes dos usuários}

Ouvidoria do Estado (1); CMS (3); opinião pública (1); conselho gestor de unidade (3); comissões internas dos CMS (2); Ministério Público (1); Pastoral da Saúde (1); promotoria da cidadania (1); coordenadorias (1).

Pode-se enquadrar as respostas acima basicamente em duas ordens: espaços internos ao SUS e espaços externos. Como espaços internos foram citados, tanto por secretários quanto por conselheiros, os seguintes órgãos: Direções Regionais de Saúde, CMS, Conselho de Secretários Municipais de Saúde, CIR, Conselhos gestores de unidades, Comissão intergestores bipartite. As DIR são vistas por alguns dos gestores municipais como espaço de poder mais pela sua ausência do que pela presença, isto é, é uma instância de poder requerida a exercer seu papel pelos municípios.

Como espaços externos temos as seguintes instituições: Ouvidoria do Estado, Câmaras Municipais, Opinião Pública, Pastoral da Saúde, Promotoria da Cidadania, Ministério Público, Associação Paulista de Medicina, Orçamento Participativo, Secretaria Municipal da Fazenda, movimentos organizados.

Chama a atenção o fato de as citações serem feitas quase que exclusivamente sob perspectiva institucional, referida quase sempre como lugares de poder, como uma coisa aonde se vai, se pergunta, a quem se apela - principalmente no caso dos aspectos externos ao setor saúde. Quase nunca são vistos como instâncias, fóruns ou espaços, o que é compreensível tendo em vista seu caráter processual, e mesmo o grau de resolutividade, lembrando que indicam, basicamente, preocupação e alcance quanto aos aspectos mais próximos aos problemas de oferta, acesso ou desempenho dos equipamentos, serviços e insumos intrínsecos à assistência à saúde.

\section{Posição dos atores sobre a} relação público/privado

\section{- Secretários municipais de saúde}

O SUS atende a todos sem distinção. Entrega de remédios com receita "de fora" do SUS encaminha-se para a Assistência Social. A relação interesferas de governo, principalmente a estadual, é problemática. Deve haver ressarcimento para todo e qualquer procedimento. O SUS deve regular o setor suplementar. Há pontes entre o setor público e privado pela ação do médico com duplo vínculo. A relação público/privado é obstaculizada pelo teto financeiro do SUS. Em razão da universalidade do SUS, o atendimento do segurado não deve ser obstruído. A relação entre os usuários e os planos deve ser regulada pelo mercado. O código de defesa do consumidor deve regular a relação do setor suplementar e os usuários. O SUS está cobrindo a alta complexidade. Plano deve ser integral e o preço também; não deve haver ressarcimento. Setor privado acha que o setor público deve pagar a conta de tudo.

\section{- Conselheiros representantes dos prestadores}

Não se deve atender possuidores de planos; maior problema na relação Estado/município está na omissão do primeiro. Não deveria haver plano. O acesso é universal no SUS, mas não deveria. Não deve haver dupla porta nos equipamentos públicos do SUS. O SUS deve ser universal e a relação com o privado deve ser de complementaridade. Há problemas entre as operadoras e as prestadoras mais do que entre as prestadoras e o SUS, pois este atrasa, mas paga, as operadoras nem sempre pagam. A relação é obstruída pela falta de diálogo do setor público com o privado, pois aquele deveria saber o que este tem para oferecer. A rigidez da pactuação dos procedimentos impede aproveitar a ociosidade do privado quanto à oferta de leitos e exames. Há incerteza no cumprimento do pactuado. O SUS é o ideal de política pública, mas quem tem plano deveria arcas com os custos; o SUS deveria atender somente urgência/emergência dos usuários de planos; há uma relação de desconfiança dos conselheiros representantes dos usuários com o setor privado.

\section{- Conselheiros representantes dos usuários}

O SUS deve ser universal. O SUS deve atender a todos, mas deve privilegiar quem não tem plano. O SUS deve atender a todos, mas quem tem plano deve procurá-los. Não deveria haver planos, não confia nos planos. O privado deve ser visto como parceiro, mas hoje a relação é de domínio do privado sobre o público, pois o alto custo vai para o SUS. É necessário o ressarcimento.

A construção dessa categoria teve como intento organizar como cada uma das partes concebe a relação público/privado e também de que maneira os princípios da universalidade e integralidade do SUS estão sendo traduzidos nas experiências cotidianas dos entrevistados.

Em termos gerais o princípio da universalidade é aceito por todos. No entanto, é necessário 
especificar as nuanças com que é apresentado e entendido. Para os secretários municipais este princípio funciona como salvo conduto para a não existência de mecanismos efetivos de regulação e controle do setor suplementar por parte das secretarias municipais de saúde. A justificativa seria o problema da base populacional quando da definição dos tetos financeiros para o custeio do SUS. Em se definindo a população SUS dependente (um dos fatores de remuneração do sistema), poderia haver a diminuição da base ocasionando possíveis quedas nos repasses do nível central para o municipal. A situação atual de não-controle sobre o setor suplementar seria funcional e adequada para o gestor municipal. Ajudaria a explicar a não identificação dos usuários do sistema suplementar, desencadear políticas de regulação que compreendam a avaliação da qualidade dos serviços prestados, a cobrança pela utilização dos serviços públicos, por meio do ressarcimento, e a análise epidemiológica da situação de saúde da população coberta pelos planos e seguros privados de saúde.

No caso dos representantes dos usuários, a questão da universalidade é igualmente aceita e defendida como necessidade, com muitas referências aos planos de saúde, que "empurram" seus beneficiários para o SUS, justamente para os níveis intermediários e de alta complexidade do atendimento, onde existe o maior gargalo no acesso.

Com exceção de um representante que entende que deve haver parceria entre os setores público e privado, os demais enxergam o setor privado como exercendo uma espécie de parasitismo sobre o público, incluindo a quebra da "fila" pelos usuários dos planos, que seriam atendidos pelos médicos com duplo vínculo que, por posição privilegiada no sistema, teriam capacidade de suplantar o esquema rotineiro de agendamento realizado pelo nível básico de atenção. Também colabora para esse fato a baixa institucionalização e normalização dos mecanismos de referência e contra-referência do SUS que coibiria esse tipo de ação individualizada.

Na análise das entrevistas comos representantes dos prestadores - em geral fortemente dependentes do SUS para sua própria viabilidade e sobrevivência financeira - verifica-se a necessidade de maior estabilidade na relação, seja no âmbito jurídico, como seu impacto no planejamento da oferta, mesmo que possa implicar maior controle sobre a prestação de serviços do setor contratado e conveniado ao SUS. Outro ponto observado é a indicação de divergências no interior da rede privada, por exemplo, a questão de custos e valores financeiros dos procedimentos, entre os operadores e os prestadores dos serviços.
O estudo aponta para a necessidade de o gestor estadual exercer funções precípuas, na coordenação, articulação, avaliação, controle e prestação de serviços de forma integrada aos sistemas de saúde locais/municipais e regional. Para a maioria dos secretários municipais entrevistados, o gestor estadual é ausente no processo de PPI como um todo, limitando-se, por exemplo, a delimitar tetos financeiros e indicar referências - muitas vezes sem levar em conta particularidades municipais, ou ainda interpretações diversas das normalizações, implicando a não regularidade dos repasses de insumos ou recursos diversos para os municípios, além da falta de projeto comum e agenda técnica para a Região Metropolitana de São Paulo.

Da leitura das entrevistas emerge que na perspectiva da Secretaria de Estado da Saúde: "todos os gestores devem fazer a regulação, de acordo com seu nível de competência ou sua função dentro do SUS", complementando que "sua atuação deve ser complementar e compartilhada com os municípios, sem ocasionar duplicidades indesejáveis". Desse modo, no exercício de "observar e inferir no sistema" 21 (p. 15) temos como destaque em suas linhas de ação: "desenvolver a eqüidade entre os municípios é uma das funções do gestor estadual e exige que sejam auxiliados prioritariamente aqueles municípios com menos recursos, decorrentes de baixo desenvolvimento econômico e com maiores problemas de saúde" 21 (p. 15, grifo nosso).

Observa-se que os gestores municipais igualmente implantaram mecanismos de organização da oferta assistencial denominados "centrais de regulação" para leitos, agendamento de consultas especializadas e procedimentos de média e alta complexidade de apoio diagnóstico. É importante frisar que a função dessas centrais municipais se refere à regulação sempre como mecanismos racionalizadores, não se efetivando em viabilização política "dos princípios da integralidade e eqüidade", como apontado no âmbito da Secretaria de Estado 21

Identificamos nos municípios pesquisados reduzida capacidade de articulação para implementar a regionalização e hierarquização da rede de serviços entre os gestores públicos, e também destes com os prestadores privados.

Outra característica da atuação do setor público estatal no mercado é que nem todos os leitos federais e estaduais existentes na região são disponibilizados para o SUS. Conforme a PAMS/2002 16, dos 285 leitos federais existentes, 199 são para o SUS e, dos 9.780 estaduais, 9.288 são para o SUS. Isto é, $30 \%$ dos leitos federais são para uso dos planos de saúde dos funcionários públicos federais e $5 \%$ dos leitos estaduais são 
oferecidos no mercado para operadoras de planos, inclusive das associações de funcionários públicos.

Os hospitais estatais que introduziram a prática de venda de seus serviços no mercado, o fizeram por meio de mecanismos jurídico-administrativos legais - as fundações públicas de direito privado. O perfil dessas instituições geralmente é composto por hospitais de excelência, que apresentam alta incorporação de tecnologia médica, como os hospitais universitários 22.

Do exposto, o tema da regulação emerge como: (i) num sentido amplo, não chega a ser vislumbrada pelos secretários municipais; (ii) referente ao setor suplementar não é espontaneamente mencionada. Induzida, traduz-se na fórmula constitucional de que "o SUS é universal“; (iii) como "estabelecimento de regras" é vista sempre de e para o setor saúde, a partir de $\mathrm{e}$ para a capacidade operacional da rede instalada. Vista para dentro, a ação regulatória do gestor incide quase que exclusivamente sobre a população, no sentido de receber, orientar, encaminhar, adscrever, ou ainda restringir serviços e procedimentos, como no exemplo mais comum, dos medicamentos.

\section{Conclusões}

Nas entrevistas pudemos ler que o único ponto consensual entre o setor público e o privado é a afirmação de que o Estado brasileiro gasta muito pouco com saúde, o que implica baixo investimento na ampliação da oferta do SUS, caracterizando uma dependência da oferta do prestador privado. Essa situação se vincula aos macrodeterminantes políticos e econômicos, tais como a responsabilização do Estado pela crise fiscal, tendo como decorrência o ajuste e a não priorização das políticas sociais.

Como dispõe a Lei Federal no. 9.656/98 10, de 1998, o ressarcimento foi a maneira encontrada para compensar o atendimento prestado aos beneficiários de planos no SUS. A opinião dos gestores entrevistados sobre o ressarcimento é divergente: para alguns os valores recebidos não compensam a estrutura que deve ser montada para sua operação, outros consideram que este mecanismo pode se revestir de importância para a obtenção de recursos.

Ao nosso ver, a operação do ressarcimento não deve ser encarada apenas como fonte de recursos, mas como um mecanismo de controle da atuação dos prestadores - além de constituir uma ação justa, do ponto de vista do gasto público.

Existem mecanismos para se exercer uma melhor regulação. No entanto, eles são pouco usados na relação público/privado, seja pelo gestor, seja pelos fóruns participativos. Os conselhos estudados sequer discutiram as questões ligadas ao setor suplementar e como a atuação das operadoras afeta a ação do SUS.

Na defesa dos interesses públicos e da saúde, como direito universal revestido de relevância pública, deve-se considerar que a vinculação das operadoras a grandes conglomerados financeiros internacionais lhes confere expressivo poder de barganha na relação com o setor público. Isso requer ação conjunta do Executivo, do Legislativo, do Judiciário, particularmente do Ministério Público, dos órgãos de defesa do consumidor e de outras formas de participação direta dos cidadãos nas formulações das políticas públicas. No SUS devem ser fortalecidos os conselhos gestores nos diversos níveis de governo.

O sistema de auditoria, avaliação e controle não foi completamente implantado, apenas criado por meio de legislação. Em contrapartida, cria-se uma agência, a ANS, como forma de resolver a questão da regulação voltada basicamente para avaliar as finanças das operadoras e não o quadro geral e os reflexos de sua ação na saúde da população.

Outra dificuldade localizada foi a relação entre os distintos níveis de governo, necessitando-se de maior articulação, acompanhamento e responsabilização dos gestores no cumprimento de suas funções públicas para a implementação do SUS e com a saúde da população. Conforme já mencionado na análise dos resultados, verifica-se uma enorme lacuna a ser preenchida pelo gestor público estadual quanto a mecanismos de avaliação, fiscalização e regulação do setor privado.

Na perspectiva da governança, o que se viu preponderantemente foi uma governança de tipo formalista, havendo uma preocupação muito grande por parte dos atores com o plano legal-jurídico das questões, cuja expressão emerge quase sempre na forma de lutas pela elaboração e aprovação de leis, normas, programas e planos.

$\mathrm{O}$ gestor, em que pese os avanços, nesse momento ainda olha para dentro do sistema de saúde, mirando apenas os serviços e os próprios da sua rede, no caso dos municípios. Com isso torna-se imensamente dependente de articulações políticas com o gestor estadual em relação à oferta e ao acesso a procedimentos de média e alta complexidade, enfim na conformação da rede de serviços.

Em relação ao uso da governança, conclui-se a necessidade de alguns pressupostos para o uso do conceito: sua aplicabilidade somente pode se dar no âmbito da formulação e implementação da política de saúde como um todo e da regula- 
ção do sistema de saúde, e não de modo descolado prescritivo, ou normativo - como uma "boa" ou "má" governança, ou ainda restrito a alguns poucos aspectos técnicos ou administrativos, ou ainda tomados por sua aparência.

Mesmo porque, democracia social ainda é algo que se apresenta muito mais como resultado de processos histórico-sociais, inclusive suas injunções regionais e mundial, econômicas, posição geopolítica ou cultural, do que de boas intenções ou modelos auto-explicativos. Um exemplo disso seria tomar, simplesmente, a "inclusão de novas demandas" ou a "inserção de novos atores no cenário" como expressão da "boa governança”, quando, na verdade, este mecanismo pode ajudar a ampliar as iniqüidades, por conta do acesso e consumo, reproduzindo e aumentando as fissuras nas teias de solidariedade e do sentimento de pertencimento da nação.

Governança se mostra como uma possibilidade importante no debate, acesso, formulação, implementação e avaliação das políticas públicas, num contínuo qualitativo quanto ao exercício e efetivação de democracia social em nosso país.

\section{Resumo}

Este artigo discute a relação público/privado no Sistema Único de Saúde (SUS) da perspectiva do gestor municipal, a partir de pesquisa cujo objetivo foi identificar estratégias e mecanismos de governança na relação público/privado do setor saúde na busca da eqüidade na Região Metropolitana de São Paulo, Brasil. Governança é ferramenta analítica. O problema éa regulação do sistema de saúde. O material para análise foi obtido por meio de entrevistas com secretários municipais e estaduais de saúde, conselheiros e técnicos do SUS. Assim, foi possivel agregar os resultados em: (a) mecanismos e instrumentos de regulação; (b) espaços de poder; $\boldsymbol{e}$ (c) posição do ator SUS sobre a relação público/privado. Há mecanismos e instrumentos de regulação utilizados nos municípios para serviços estatais. Para o setor complementar e suplementar a ação regulatória, neste nível de gestão, praticamente inexiste. Os espaços de poder institucionais são inúmeros e reconhecidos como lugares para encaminhamento de demandas mais do que fóruns de pactuação. Apesar dos avanços, a governança se apresentou como de tipo formalista. O debate da regulação na relação público/privado mostrou-se necessário para avanços na gestão do sistema.

Sistema Único de Saúde; Sistemas de Saúde; Gestão em Saúde

\section{Colaboradores}

Todos os autores participaram das diferentes etapas da pesquisa e da elaboração do artigo.

\section{Agradecimentos}

Ao International Development Research Centre (IDRC), Canadá, com gerência financeira da Red de Investigación em Sistemas e Servicios de Salud del Cono Sur, pelo auxílio finaceiro à pesquisa Desafios para a Eqüidade em Saúde na Região Metropolitana de São Paulo, da qual todos os autores participaram. 


\section{Referências}

1. Azevedo S. Federalismo e reforma do Estado: resultados preliminares de pesquisa. In: Seminário A Reforma da Administração Pública no Brasil: Possibilidades e Obstáculos. http://www.fundaj. gov.br/docs/eg/semio.html (acessado em 28/ Nov/2004).

2. Ministério da Administração Federal e Reforma do Estado. Plano diretor da reforma do aparelho do Estado. Brasília: Presidência da República; 1995.

3. Bresser-Pereira LC. A reforma do Estado nos anos 90: lógica e mecanismos de controle. Lua Nova: Revista de Cultura e Política 1998; 45:49-95.

4. Bresser-Pereira LC. Um novo Estado para a América Latina. Novos Estudos - CEBRAP 1998; 50:91-8.

5. Ministério da Saúde. Lei Orgânica da Saúde no. 8.080, de 19 de setembro de 1990. Dispõe sobre as condições para a promoção, proteção e recuperação da saúde, a organização e o funcionamento dos serviços correspondentes e dá outras providências. Diário Oficial da União 1990; 20 set.

6. Ministério da Saúde. Lei no. 8.142, de 28 de dezembro de 1990. Dispõe sobre a participação da comunidade na gestão do Sistema Único de Saúde (SUS) e sobre as transferências intergovernamentais de recursos financeiros na área da saúde e dá outras providências. Diário Oficial da União 1990; 31 dez.

7. Ministério da Saúde. Portaria no. 545, de 20 de maio de 1993. Norma Operacional Básica - NOB 01/1993. Diário Oficial da União 1993; 24 mai.

8. Ministério da Saúde. Portaria no. 2.203, de 5 de novembro de 1996. Norma Operacional Básica - NOB 01/1996. Diário Oficial da União 1996; 6 nov.

9. Ministério da Saúde. Portaria no. 373, de 27 de fevereiro de 2002. Norma Operacional da Assistência à Saúde - NOAS 01/2002. Diário Oficial da União 2002; $28 \mathrm{fev}$.

10. Ministério da Saúde. Lei no. 9.656, de 3 de junho de 1998. Dispõe sobre os planos e seguros privados de assistência à saúde. Diário Oficial da União 1998; 4 jun.

11. Salgado LH. Agências regulatórias na experiência brasileira: um panorama do atual desenho institucional. Brasília: Instituto de Pesquisa Econômica Aplicada; 2003. (Texto para Discussão, 941).

12. Hufty M. Gobernanza. Hacia un concepto. http://www.idrc.ca/uploads/user-S/1103577915 1presentation_Hufty-CRDI.pdf (acessado em 12/ Dez/2004)
13. Programa das Nações Unidas para Desenvolvimento/Instituto de Pesquisa Econômica Aplicada/Fundação João Pinheiro/Instituto Brasileiro de Geografia e Estatística. Atlas do desenvolvimento humano no Brasil [CD-ROM]. Brasília: Programa das Nações Unidas para Desenvolvimento; 1998.

14. Heimann LS, Pessoto UC, Junqueira V, Castro IEN, Kayano J, Nascimento PR, et al. Quantos Brasis? Eqüidade para alocação de recursos no SUS. São Paulo: NOAR Estudios/Instituto de Saúde; 2002.

15. Fundação Sistema Estadual de Análise de Dados. Índice paulista de responsabilidade social - para o Fórum São Paulo século XXI. http://www.seade. gov.br/hpseade/iprs/IPRS.pdf (acessado em 22/ Nov/2005).

16. Instituto Brasileiro de Geografia e Estatística. Pesquisa de assistência médico sanitária: estatísticas de saúde [CD-ROM]. Rio de Janeiro: Instituto Brasileiro de Geografia e Estatística; 2002.

17. Fundação Sistema Estadual de Análise de Dados. Pesquisa de condições de vida, 1998 - São Paulo. http://www.seade.gov.br/cgi-bin/pcvv98/pcv_ 01.ksh (acessado em 30/Nov/2005).

18. Departamento de Informação e Informática do SUS. Informações em saúde para o ano 2003. http://www.datasus.gov.br (acessado em 30/ Nov/2005)

19. Agência Nacional de Saúde Suplementar. Informações sobre operadoras de planos de saúde para o ano de 2004. http://www.ans.gov.br (acessado em 29/Nov/2005).

20. Thiollent $\mathrm{M}$, organizador. Opinião pública e debates políticos: subsídios metodológicos. São Paulo: Editora Polis; 1986.

21. Barata LRB, Tanaka OY, Mendes JDV. O papel do gestor estadual no Sistema Único de Saúde. São Paulo: Secretaria de Estado da Saúde de São Paulo; 2003.

22. Centro de Estudos de Cultura Contemporânea. "Subsídio cruzado" ou “ dupla porta”: o público e o privado no Hospital das Clínicas de São Paulo. São Paulo: Centro de Estudos de Cultura Contemporânea; 2002. (Série Didática, 6).

Recebido em 02/Jun/2005

Versão final reapresentada em 17/Fev/2006

Aprovado em 25/Abr/2006 